\title{
Innovative Design and Research on the Landscape in the Living Room of Distinctive Small Towns Based Upon the Multi- Dimensional Cultural Visualization Technology*
}

\author{
Ying Yuxi ${ }^{1, \mathrm{a}}$, Tian Mimi ${ }^{\dagger 1, \mathrm{~b}}$ \\ ${ }^{1}$ College of Design and Architecture ZheJiang University of Technology, China, Hangzhou
}

\begin{abstract}
Benefited from the development of distinctive small towns in China, the visualized performance on the cultural characteristics of parlor landscape in distinctive small towns has drawn increasingly attention. In view of the absence of individuality in cultural elements, irrespective of the landscape space relations, monotonous cultural experience approaches and other existed problems on parlor landscape in towns, this paper integrated the survey of cases to summarize three design techniques which consisted of refining the cultural connotation, evolving the cultural space as well as activating the cultural show. In the meantime, it focused on studying the application of dynamic digital technology to reinforce the multi-dimensional visualization of culture, thus providing fresh ideas for the parlor landscape design in distinctive small towns.
\end{abstract}

\section{Introduction}

The living room in distinctive small towns is perceived as the gateway to the towns. The creation of its landscape style and features along with the reflection of cultural characteristics have been regarded as the identifiable visual indexes to the peculiarity of small towns. As visualization progressively becomes the dominant stream of cultural spread. It definitely requires to convey the cultural connotations of living rooms in distinctive small towns through the most effective and intuitional visualization form of culture as well. This paper focuses on studying the subject that uses the multi-dimensional cultural visualization technique to present the identifiable landscape style and features of the living rooms in the midst of designing the living rooms of "all towns in the same pattern" distinctive towns.

\section{Related Conception}

\subsection{Cultural Multi-Dimensional Visualization Technology}

The Cultural visualization technology uses visual approach to display the connotations in culture technically.

Previously relevant cultural visualization technologies were limited to bi-dimensional aspect, that is, they transformed the culture into graphical format then expressed via carriers. By contrast, the cultural visualization technology focuses on cultural symbolization by proposing multilevel and multi-angle visual technique. It is opposed to single and extraordinary regional culture and advocates cultural diversity. The

ayingyuxi123@qq.com

btianmimi518@163.com elaborated culture in this paper referred to the visual expression of culture in landscape design through multidimensional technique. (Shown in Figure 1)

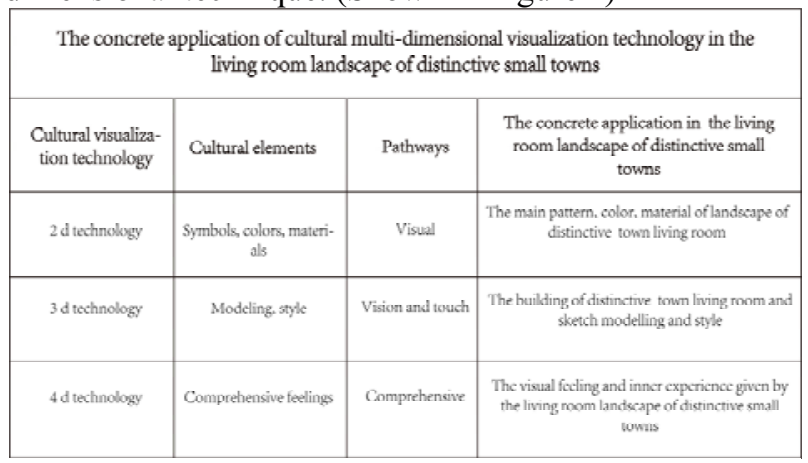

Figure 1: The concrete application of cultural multidimensional visualization technology in the living room landscape of distinctive small towns

\subsection{Concept of the Distinctive Town Living room}

The idea of "distinctive town living room" borrows from the expression of "urban living room". In a narrow sense, "distinctive town living room" refers to the central plaza and its supporting facility. In a broad sense, it is the core social public space in distinctive towns. The distinctive town living room exists as the window to show its image and feature to the outside world. Thereupon, it is essential to reinforce the uniqueness by integrating the regional cultural features into the landscape design. External display function and the user experience are supposed to be satisfied at the same time, thus bringing the spatial sense of belonging to people who experience it. 


\subsection{Cultural Value of the Distinctive Town Living Room}

Rooted by the regional culture, the distinctive town living room possesses its uniqueness. The culture endows it with landscape connotations. Therefore, in the absence of some cultural connotations, the landscape of town living room is empty and unattractive. Eventually such design will be replaced with the development of times. By integrating the multi-dimensional cultural visualization technology, strong cultural atmosphere is created to construct a perfect seeking-root place for the experiencers.

\section{Current Situation of Distinctive Town Living Room}

\subsection{Absence of Personality in Bi-Dimensional Cultural Elements}

At present, a majority of the landscape designs for the distinctive town living room are absent from originality and regional culture. Most of the cultural elements are presented as "borrowlism". That is, the relationship between the landscape and the cultural elements is hardly found in terms of function and semantics. Moreover, the regional culture is not considered in present design, thus leading to severe homogeneity on the town living rooms. In view of above, it mainly results from the insufficiency in digging into local culture and the cultural connotations so as to limit the extendibility of landscape design.

\subsection{Absence of Correlation in Tri-dimensional Landscape Space}

The support from landscape space is necessary to create the landscape style and features in distinctive small town living room. However, for current small town living rooms, they possess single space which is absent from diversely cultural narration. In most cases, the landscape space is expressed by the collage of scattered regional cultural images and symbols. Even if each carrier possesses specific cultural theme element, merely piling them up may only cause irrelevance in space. Consequently, the cultural perception of experiencers will become numb step by step.

\subsection{Single Approach on Four-Dimensional Cultural Experience}

In nowadays landscape design of distinctive small town living room, the emotional communication between the experiencers and the culture is shallow. Mostly the culture is merely displayed in sculpture, landscape facilities and other forms, part of the cultural sculptures are just duplicates of the original form. The experiencers cannot obtain more relevant information about local culture unless they observe the sculptures, and they also cannot understand its cultural connotations. The experiencers tend to accept passively by placing themselves in such kind of distinctive small town living rooms, accordingly it affects their cultural experiences.

\section{Case Analysis}

Culture is the soul of the landscape in distinctive small town living room. And the latter is the most intuitive carrier of culture. The major application of multidimensional cultural visualization technology on the landscape of current distinctive small town living room comprises three aspects: expression for cultural elements, spatial style design, immersive cultural experience.

\subsection{Expression of Cultural Elements}

In most circumstances, current distinctive small towns purely absorb local culture to show the cultural elements. They neglect the human demands on the implication of regional cultural symbols. For instance, the Hehe small town on Tiantai Mountain regard local Buddhist culture as its landscape element directly. By exaggerating the landscape articles abruptly as well as placing the celebrity sculpture everywhere in the small town living room, it presents simplified and stereotyped trend. This design lacks in creation that fits the aesthetic standards in the new era. So it is difficult to attract the experiencers in participation and interaction. In the meantime, people are prone to visual aesthetic fatigue.

\subsection{Spatial Design of Landscape}

The design style of many earlier distinctive small town living rooms ignored local culture. These architectures attempt to catch experiencers' attention by 'European cultural flavor". In the end they were relegated to "isolated towns" that nobody likes. For some landscapes with context in distinctive small town living rooms, the designers are enthusiastic about using black bricks and tiles to bring about "all towns in the same pattern". For example, the Austria small town in Huizhou city, Guangdong province aims to attract the attention by blindly imitating the European architectural style. It simply simulates the appearance and abandons local cultural features, thereupon losing the cultural connotations. Likewise, unsuccessful cases are: Longtan water small town in Chengdu city hadn't paid enough attention on the cultural connotations. In the design, it simply imitated the style of Suzhou Classical Gardens by causally piecing the architectures together. And the details were not processed properly. Therefore, it caused the landscape of the distinctive small town living room to go against the local living environment and the regional space; The same is true of the Donghuang small town in Xianyang city which is just an imitation of successful cases. Though being alike from the outside, it lacked in real features of its own, and eventually ended in failure.

However, there are many successful cases among designs. For example, the architectural design in the Dream Small Town living room of Hangzhou city reveals the "white wall black tiles" visual effects of the southern building complex. In case of in-depth research, the unique qualities for the small town culture in Zhejiang province 
are presented in the town living room by the "grey tiles white walls", the originally wooden colored doors and windows as well as other forms. The architecture perfectly brings Jiangnan culture alive. And this presentation inherits and develops traditional Jiangnan culture under modern background. Moreover, it cultivates within its characteristics the architectural image which meets the current of times. The "Nianhua Bay" small town in Lingshan city used local materials (Mount Huang rocks, traditional wooden materials, thatches, etc.) to build its town living room. In addition to emphasizing on natural taste, one most important part is that, the spatial topics of the small town living room possesses relatively stronger regional features. It expresses the aesthetic ideas of Buddhist culture through modern landscapes. As of the rural landscape of the celadan small town in Longquan city, it skillfully integrates the industrial texture into celadan elements. In architecture, the vertical texture is built by the celadan glazed curtain wall and the celadan to realize the connection of new and old building materials.

\subsection{Immersive Cultural Experience}

The presented culture in the landscape of distinctive town living room can form an ideology under immersive experience. In it, culture is the internal motivation; and the immersive cultural experience is the foundation for experiencers to feel its cultural connotations. Take the China Longquan Celadan Town for example, by spatially grafting the celadan culture, production process, old workshop and other material carriers, it designed a funny tour route which was filled with both historical culture and modern experience (Shown in Figure 2).

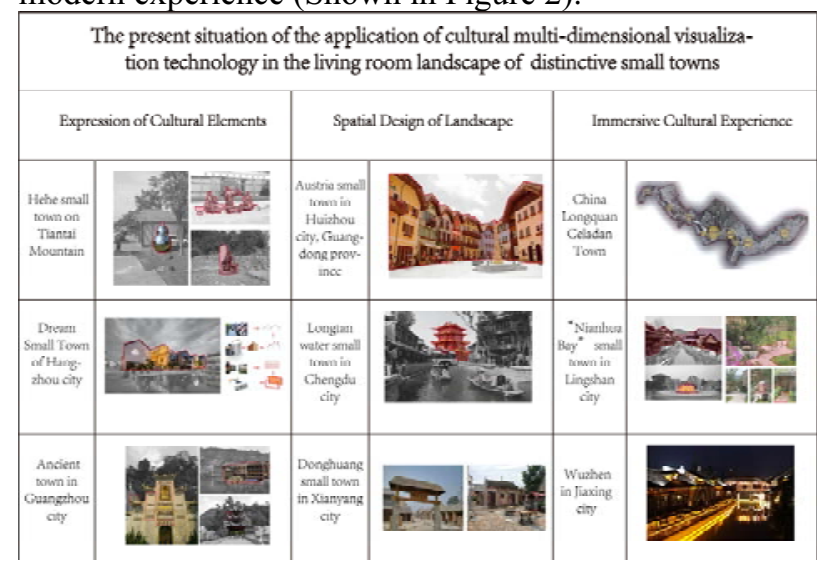

Figure 2: The present situation of the application of cultural multi-dimensional visualization technology in the living room landscape of distinctive small towns

The experiencers will definitely provide a less sense of belongings if the culture and character of distinctive town living rooms are ignored. Today, the features of the landscape in distinctive town living room are also successively fading away. Instead the reproduction culture is taking its place. It's the designers' responsibility to continue passing on the regional culture in the distinctive town living room with multi-dimensional visual technology. Otherwise, the distinctive small town living room will eventually end in failure once there is insufficient creation on culture in it; or it concentrates on blindly copying and imitating to catch visual effects.

\section{Innovative Design Methods on the Landscape of Distinctive Small Towns}

\subsection{Refining of Cultural Connotations}

The regional culture in distinctive town living rooms is bound to collide with foreign cultures under globalization trend. Thereupon, it is essential for us to dig into the cultural connotations and proactively integrate and innovate with foreign cultures. It also needs to use modern aesthetic ideas to transform the "shape", refine the "color" and borrow the "material" to produce new cultures.

5.1.1 Conversion of "Shape". The modern context is recombined and converted into specific images by intercepting partial style or symbol from the primary form of regional culture; or through processing some excessively complicated cultural forms by simplification, deformation, reconstitution, abstract and other methods. The newly created cultural landscape elements are compliant with current aesthetic needs. In the midst of designing the dream-seeking ancient town bridge located in the Small Dream Town of Hangzhou city, the bridge elements in the Ming and Qing dynasties were refined and borrowed. Through deformation and rebuilding, the cultural atmosphere of the landscape bridge was also improved when it meets the traffic functions. It needs to be noted that, excessive transformation of cultural forms will have an impact on the cultural discernibility.

5.1.2 Refining of "Color". The landscape culture of distinctive small town living room cannot do without colors. Regional culture and historical background work together to influence the colors of landscape. Nevertheless, besides refining colors in large areas, the modern digital method realizes the application of colors from dark to light. Different visual effects can be presented at various eye levels. Affected by the color creation method in traditional Chinese architect and inspired by "the law of nature in Taoism", China Pavilion uses four types of red colors from outside and three types of red colors from inside to create layer-level gradual changes. Accordingly, the experiencers obtain different sensory experiences from various viewing angles. This provides references for the color application in the landscape of the distinctive small town living room.

5.1.3 Refining of "Color". Here the "materials" refers to the distinctive natural resources. They gradually take shape in the process of cultural development. However, the traditional wooden material, natural stone materials, bricks and tiles possess relatively inferior performance of endurance and fire resistance. It is favorable to skillfully use the creative technique to reprocess natural resources or combine them with fair-faced concrete, glass and other new materials. As a result of the massively innovative concept, i.e. the conversion of material textures, the 
materials are endowed with more novel senses.

\subsection{Activation of Cultural Space}

\subsubsection{Evolution of Culture in Landscape Space. A} number of details in the landscape space of distinctive town living room reflect its regional culture. Therefore, in the midst of evolution, local decorative patterns, ridge ornament or miniature map are used to combine with the pavement, landscape wall or characteristic system. It aims to deliver the cultural information to the experiencers imperceptibly from both overall and details. Simultaneously the cultural-style tiny facilities are placed in the landscape space of the small town living room to brighten the environment.

5.2.2 Cultural Evolution in Architectural Space. The architectural space is a key subject in the cultural evolution of the distinctive small town living room. After collection and arrangement, the cultural elements are used to produce virtual-real comparison. The aesthetic architectural space is then created and new artistic image is introduced into the space. The selection and creation of views are also indispensable to ensure extraordinary culture evolution in the architectural space. It demands native environment as carriers to motivate the mindset of experiencers and appropriately present complex cultural elements in narrative method. In most designs of the distinctive small town living rooms in northern part of Zhejiang province, the local traditional techniques and modern environment-creating elements are combined in the architectural space. Moreover, each space has been linked together to strengthen the overall atmosphere of architectural space and the expression of cultural features.

\subsection{Activation of Cultural Show}

In the landscape of distinctive small town living rooms, the culture is supposed to show the new "living" tendency. Among it, "living" consists of two meanings: on the one hand, by means of dynamic digital technology, the experiencers feel flexible and multi-dimensional forms of experience when they visit the small town living room; on the other, the culture is endowed with fresh digital life, which brings the regional culture "alive" in its landscape. So the dynamic digital technology makes significant contribution in the cultural activity shows.

At present, under the help of the immersive cultural display technique, the photographers can take photos as per the point positions in the living room of distinctive small town, then upload onto the network server. The back stage cuts the photos and montage them until the accessible panorama is produced; Again tri-dimensional rebuilding technology is used to generate the model which will display on the cellphone or VR devices of experiencers. Furthermore, via the presentation style of the landscape in innovative small town living room, the landscape along with the sound, electricity, lights and more devices are merged together to create the interactive landscape articles. It aims to develop new pattern of nightscape in the small town living rooms. In addition to enhancing the experiences, it can also spread local culture and improve the sense of new era in larger scope. The "living" show of culture can inspire the experiencers' spontaneous curiosity and desires to explore the living room of distinctive small towns, thus attracting more visitors and injecting the distinctive small towns with vitality.

\section{Conclusion}

The most fascinated part of the living room in distinctive small towns stems from its regional cultural characteristics. The unique image of small towns is created by the multidimensional cultural visualization, which combines the refining of cultural connotations, the evolution of cultural space and the activation of cultural exhibition together. Under the background of new era, the users' aesthetic habit and cultural demands have increasingly improved. Therefore, only if the cultural connotations are profoundly explored and the innovative cultural landscape is created as well as the dynamic digital technology is applied to display the "living" culture, can culture become alive and further improve the uniqueness of the living rooms in distinctive small towns.

\section{Acknowledgment}

Research Project by the Ministry of Education Humanities and Social Science "Research on the Environmental Designing Strategy in Distinctive Towns Based Upon Ecology and Cultural in Parallel" (18YJC760078)

\section{REFERENCES}

1. Yu Jianzhang, Ye Shuxian. Symbol: Language and Arts [M]. Shanghai: Shanghai People Press, 1988.

2. Zhao Yiheng. Semiology [M]. Nanjing: Nanjing University Press. 2012 (10): 66-88.

3. Liu Zhanglu. Probe into the Cultural Values and Connotations in Distinctive Cultural Tourism Towns [J].

Consultant on farming wealth acquisition, 2019, (22). 286.

4. Huang Kun. Research on the Application of She Ethnic Culture in the program of Jiangxi Longgang. Tourism and Customs Distinctive Towns. [D]. Zhejiang Agricultural University, 2019.

5. Liu Weili. Exploration on the Landscape Building Approach in Distinctive Town Construction. [J]. Modern Gardening, 2017 (22).

6. Tai Jie. Study on the Landscape Design of Distinctive Towns [J]. Northern Architecture, 2018 (3).

7. Zhang Qian. Brief Analysis on the Expression of Distinctive Town Style and Features from the Perspective of Regional Culture [J]. Green Environmental Construction Materials, 2020 (1).

8. Ke Yukai. Research on the Landscape of Chinese 
Distinctive Towns [D]. Hubei Institute of Fine Arts, 2018.

9. Song Yiwen. Research on the Landscape Design on the Basis of Regional Culture [D]. Jiangxi Agricultural University, 2018.

10. Ma Tengyun. Research on the Landscape Application and Regional Cultural Symbols in Guanzhong Distinctive Towns [D]. Chang'an University, 2018.

11. Gong Jiejie. Research on the Programming of the Distinctive Towns from Cultural Perspective [D]. Huazhong University of Science and Technology, 2017. 